\title{
Breast-conserving treatment in oncoplastic times: indications, cosmesis, and quality of life
}



\section{ABSTRACT}

Breast-conserving treatment was established as an oncologically safe procedure for breast cancer. However, the cosmetic outcomes of breast-conserving treatments are often unsatisfactory. In this scenario, oncoplastic breast-conserving surgery incorporated plastic surgery concepts and techniques into the oncological treatment in order to ensure better cosmesis, thus increasing the indications for breast-conserving treatment. At the same time, oncoplastic breast-conserving surgery is usually presented as a generic term, which should be evaluated taking many aspects into account: indication, patient selection, the surgery itself, cosmetic quality, and quality of life - data that are still scarce in the literature.

KEYWORDS: breast neoplasms; mastectomy, segmental; conservative treatment; surgery, plastic; cosmetic techniques.

\section{INTRODUCTION}

The surgical treatment of breast cancer is one of the only oncological areas in which other people besides the patient will judge the cosmetic outcome in the same way the oncologic result is assessed. The woman will have her breasts evaluated by radiotherapists, radiologists, gynecologists, mammography technicians, among others. Thus, we cannot address breast cancer surgery without its associated esthetic criterion ${ }^{1}$.

For many years, radical mastectomy was the only surgical treatment offered for breast cancer. However, when Fisher et al. compared mastectomy, lumpectomy, and lumpectomy followed by breast radiotherapy in a randomized trial, they found no significant differences regarding disease-free survival, distant-diseasefree survival, or overall survival among the 3 groups, even after 20 years of follow-up². Likewise, between 1973 and 1980, Umberto Veronesi compared quadrantectomy associated with radiotherapy and mastectomy, and, once again, the results overlapped ${ }^{3}$.

With the establishment of breast-conserving treatment (BCT) associated with the increase in early diagnosis, the advance in systemic therapies, and the consequent increase in patient survival, the analysis of surgical treatment transcended purely oncologic issues ${ }^{4}$.

Surgeons started to look into improving the cosmetic quality of the procedure. After all, up to $30 \%$ of patients submitted to quadrantectomy need late reconstruction due to unsatisfactory esthetic outcomes $^{5}$. Thus, oncoplastic breast-conserving surgery (OBCS) emerges to improve the cosmetic results of breast cancer surgeries. OBCS is usually presented as a generic term, involving procedures associated with both BCT and reconstruction after mastectomy. Nonetheless, it should be contextualized in each analysis and evaluated based on many aspects: indication, patient selection, the surgery itself, cosmetic quality, and quality of life (QoL) (Figure 1) . $^{6}$

Figure 2 illustrates the results between symmetry (Figures 2A and $2 \mathrm{C}$ ) and bilateral surgery (Figures $2 \mathrm{C}$ and $2 \mathrm{D}$ ), traditional surgery (Figure 2A and 2B) and OBCS (Figures 2C-2D), in addition to important breast tissue changes after radiotherapy, such as skin edema and fibrosis (Figure 2B), justifying the discussion on the subject.

\section{ONCOPLASTIC BREAST-CONSERVING SURGERY}

From an oncological point of view, OBCS allows initial candidates for radical treatment to receive conservative treatment. It enables large resections, with possible wider margins, which could lead to lower rates of positive margins without compromising esthetic results ${ }^{6}$. Many initial contraindications for BCT have become relative after OBCS, such as tumors larger than $5 \mathrm{~cm}$ and local skin infiltration, provided the margins are satisfactory and the breast volume allows the procedure.

\footnotetext{
'Department of Mastology and Breast Reconstruction, Hospital de Câncer de Barretos - São Paulo, Brazil

2Postgraduate Program in Obstetrics and Gynecology, Faculdade de Medicina de Botucatu, Universidade Estadual Paulista "Júlio de Mesquita Filho" - Botucatu (SP), Brazil.

${ }^{3}$ Department of Oncological Surgery, Mastology Division, Hospital de Câncer de Muriaé - Minas Gerais, Brazil.

*Corresponding author: reneacv@terra.com.br

Conflict of interests: nothing to declare.

Received on: 06/17/2020. Accepted on: 08/28/2020.
} 
However, long-term follow-up data on recurrence, cosmetic results, or QoL are scarce ${ }^{4}$.

Most published series evaluates the OBCS applicability to tumors that require a small surgical resection due to their reduced size. Silverstein et al. described the term "extreme oncoplasty" for cases with an initial indication for mastectomy, but that were submitted to OBCS. After assessing 66 patients with tumors whose mean size was $77 \mathrm{~mm}$, they found similar recurrence to that of patients with small tumors?

Another factor contributing to a higher indication of BCT was the neoadjuvant chemotherapy for breast cancer, even in the presence of locally advanced tumors. Nevertheless, a good cosmetic result after surgery is expected by this group of patients. Thus, OBCS has achieved good cosmetic results even in more



OBCS: oncoplastic breast-conserving surgery; BCT: breast-conserving treatment. Source: adapted from Oliveira-Junior et al. with authorization ${ }^{6}$.

Figure 1. Outcomes involved in oncoplastic breast-conserving surgery. extensive resections of locally advanced carcinomas, representing a satisfactory option to avoid radical surgery, whose morbidity is higher8. Vieira et al. conducted a matched case-control study with a mean follow-up of 67.1 months, revealing that patients with locally advanced tumors submitted to neoadjuvant chemotherapy and OBCS showed no difference regarding local and locoregional recurrence and overall survival compared to $\mathrm{BCT}^{4}$.

Any patient eligible for breast-conserving surgery, with appropriate size and ptosis in relation to tumor size, should be considered a candidate for $\mathrm{OBCS}^{9,10}$. However, the selection of patients submitted to these procedures shows an important bias. They tend to be performed in young ${ }^{11}$ and more educated patients, who might demand a better cosmetic result ${ }^{4}$.

Several observational studies have evidenced the association between OBCS and lower rates of positive surgical margins. A recent meta-analysis by Losken et al. indicated that OBCS could halve the rate of positive margins $(12 \% \text { vs. } 21 \%, \mathrm{p}<0.0001)^{12}$. Consequently, it might reduce the rate of surgical re-excision, as shown by Down et al. $(5.4 \% \text { vs. } 28.9 \% \text {, } \mathrm{p}=0.002)^{13}$. Another metaanalysis involving 18 studies found no significant difference concerning reoperation between the OBCS and BCT groups after adjustment for publication bias ${ }^{11}$.

Based on the assumption that the oncological safety of OBCS should be similar to that of standard treatment ${ }^{14}$, Rietjens et al., in 74 months of follow-up, detected $8.4 \%$ recurrence in patients with pT2-3 tumors submitted to OBCS, whereas pT1 patients had no recurrence ${ }^{15}$. Another study identified local recurrence of $4.3 \%$ in OBCS and 3.7\% in $\mathrm{BCT}^{16}$. Clough et al. found a 5-year cumulative incidence of $2.2 \%, 1.1 \%$, and $12.4 \%$ for local, locoregional, and distant recurrence, respectively ${ }^{17}$. We emphasize that tumors are approximately $3 \mathrm{~cm}$ in size in most series that evaluate $\mathrm{OBCS}^{4,17}$.

A meta-analysis including 11 studies compared the oncologic results between BCT and OBCS, with a total of 3,789 cases (2,691 patients in the BCT group and 1,098 in the OBCS group) without significant difference between pathological staging, and found that local and distant recurrence rates were similar in both groups. Overall survival data also revealed non-inferior effects of OBCS compared to BCT ${ }^{18}$.

In a meta-analysis involving 18,103 patients with mean follow-up time ranging from 1.5 to 9.2 years, Kosasih et al. found no significant difference between BCT, OBCS, and mastectomy (relative risk $-\mathrm{RR}=0.861 ; 95 \%$ confidence interval $-95 \% \mathrm{CI}$ $0.640-1.160 ; \mathrm{p}=0.296$ ) regarding recurrence ${ }^{11}$.

The comparison between BCT and OBCS in 8,659 patients (3,165 in the OBCS group and 5,494 in the BCT group) showed that the surgical specimen weight and the tumor size were higher in the oncoplastic group ( $2.7 \mathrm{vs.} 1.2 \mathrm{~cm}$ ), which also presented significantly lower positive margins and re-excision rates. Nonetheless, local recurrence was $4.2 \%$ in the OBCS group and $7 \%$ in the BCT group ( $\mathrm{p}<0.0001)$, although follow-up was longer in the BCT group (64 vs. 37 months) $)^{12}$. 


\section{SURGICAL TECHNIQUES AND STRATEGIES}

OBCS incorporated plastic surgery concepts and techniques into the surgical treatment of breast cancer, becoming associated with the excision of breast parenchyma and the simultaneous reconstruction/reshaping of the defect in order to avoid local deformities. Therefore, a variety of techniques can be performed in BCT, extending its indications. In addition, by reducing the parenchyma, oncoplastic techniques promote the effectiveness of radiotherapy in the remaining tissue, with dose homogeneity and acceptably low complication rates ${ }^{19,20}$.

In our field, Andrade Urban developed a classification based on technical skills to improve the training of surgeons. It consists of three distinct skills:

- Class I covers glandular mobilization and reshaping, without requiring specific surgical training;

- Class II demands specific training because it involves skills related to breast reconstruction with implants, mastoplasty, and mastopexy, usually bilateral for symmetrization;


Figure 2. Breast-conserving treatment. (A) Symmetry and conservative treatment on the right breast; (B) asymmetry and conservative treatment on the left breast; (C) good symmetry in conservative treatment and symmetrization (D) asymmetry in conservative treatment with oncoplastic technique — plug flap — and symmetrization.
- Class III encompasses autologous flaps or a combination of techniques, requiring specific training ${ }^{21}$.

Other classifications for oncoplastic procedures have been proposed. The one by Clough et al. divides the technique into two levels, based on the complexity of the procedure. "Level 1" techniques are based on glandular mobilization and repositioning of the nipple-areola complex, with less than $20 \%$ of the breast volume resected. Those classified as "level 2 " involve resections ranging from $20 \%$ to $50 \%$ of the breast volume and are divided into volume repositioning techniques (therapeutic mammoplasty) and volume replacement techniques (fascia or myocutaneous flaps), associated or not with contralateral mammoplasty $^{8,22}$. The American Society of Breast Surgeons, in consensus, also opted for this definition and classification system of OBCS based on anatomy and volume, as it applies to most techniques described in the literature. However, the classification should act as a practical guideline for surgeons rather than a strict rule, as underlined by the committee ${ }^{23}$.
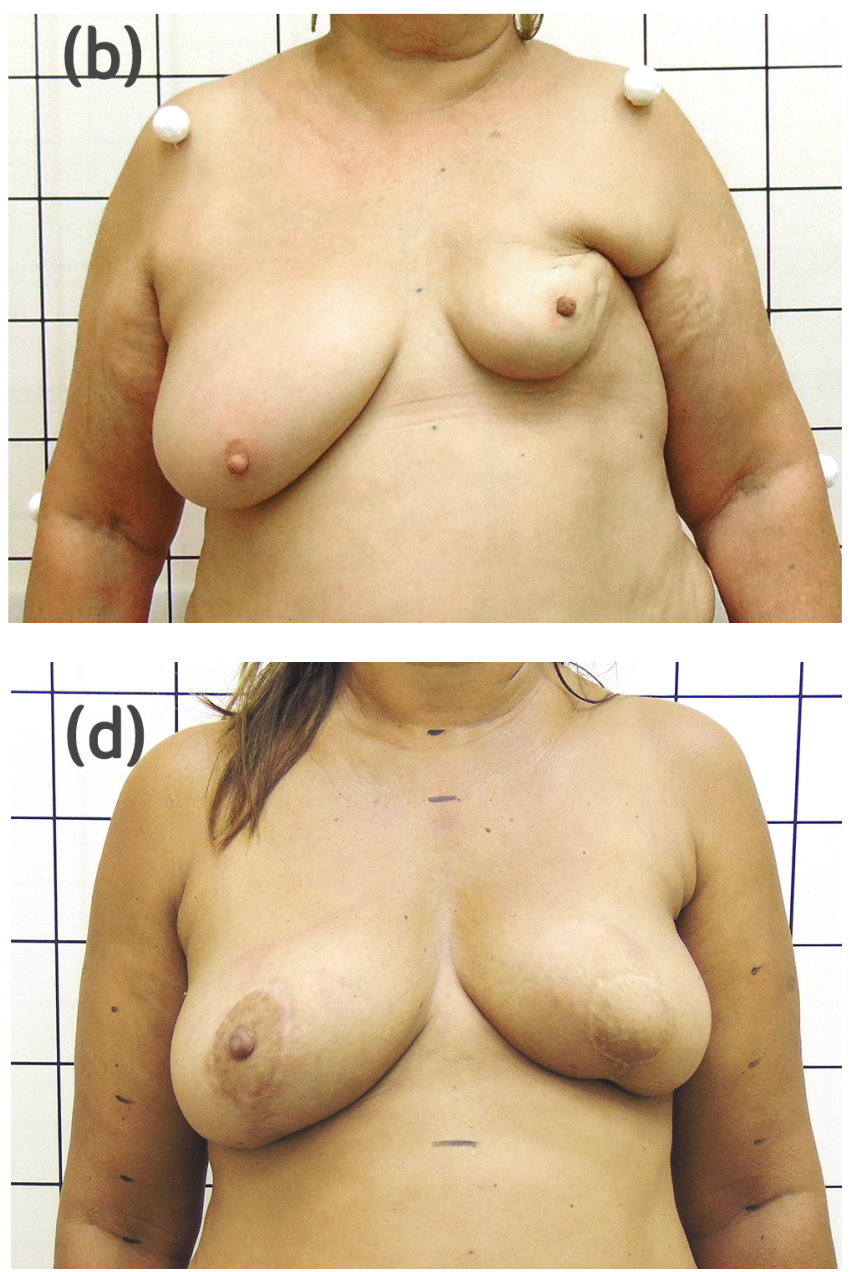
Training schools have divergences as to OBCS classification. In the "First International Consensus Conference on Standardization of Oncoplastic Breast Conserving Surgery", experts, mostly Europeans, voted to adopt the Clough classification as the standard for clinical practice (indication, planning, and performance of the procedure $)^{24}$. Nonetheless, for billing purposes, the consensus was to use the classification by Hoffmann et al. ${ }^{25}$, which is based on the complexity of the breast surgical procedure, whether oncologic, oncoplastic, or reconstructive. Still, they disagreed on which classification should be recommended as the best standard for clinical research ${ }^{24}$.

Weber et al. proposed nomenclature and algorithms to help surgeons standardize the ideal OBCS procedure. The procedures were classified as conventional tumorectomy (glandular reapproximation and direct closure of the surgical wound), mastopexy (non-oncological skin resection and nipple repositioning, with or without pedicles), oncoplastic tumorectomy (glandular reshaping and volume replacement), and oncoplastic reduction mammoplasty (non-oncological breast reduction, with repositioning of the nipple-areola complex through pedicles). The two proposed algorithms - indication and reconstruction - are targeted at surgical planning according to breast size and shape, tumor size and location, vascular supply to suggest flaps, glandular reshaping, and specific pedicles to replace the resected volume ${ }^{26}$.

Regardless of the classification adopted, conservative treatment involves class I and II procedures, favoring the training of mastologists and the development of centers directed at this training in Brazil ${ }^{27}$.

Whether OBCS falls within the competence of the mastologist, surgical oncologist, or plastic surgeon is debatable. In Brazil, similar to other countries, professionals participate cooperatively in most cases. Nonetheless, this scenario can differ significantly: most women undergoing surgical treatment of breast cancer do not have access to reconstruction. Each surgical specialty has its usual advantages, but training should be required for OBCS to ensure oncological safety and superior cosmetic outcomes ${ }^{21}$.

The surgeon must choose the surgical technique taking into account the tumor characteristics and the breast morphology, besides the developed expertise, not forgetting the patient's cosmetic expectations, considering the lack of a single formula for the surgery. Breasts vary considerably, resulting in several possibilities to solve the challenges posed by the tumor.

Regarding BCT, given the diversity of procedures, several authors have attempted to exemplify them based on breast volume $^{28}$, quadrant location ${ }^{22,29}$, technique selected according to algorithms $\mathrm{s}^{24}$, variety of techniques ${ }^{30}$, development of new techniques $^{10,31}$, and application to extensive surgeries ${ }^{7}$. Thus, the large number of techniques, ranging from small local parenchyma reshaping to elaborate resections, made the term OBCS very generic, combining various possible surgical outcomes, with different levels of complexity, into a single category. In this respect, several techniques are grouped, and given the lack of a standard, the literature has room for analyses and comparisons. Moreover, the theoretical-practical concept of oncological safety associated with the cosmetic result is recent and needs improvement $t^{4,10}$.

Therefore, in BCT, oncoplasty involves care related to oncological treatment versus adequacy of the volume in the affected breast associated with the secondary adequacy of the volume in the contralateral breast ${ }^{1}$. Breast-conserving surgery often results in breast asymmetry, which is related to worse postoperative QoL and worse psychosocial functions; after all, the cosmetic result has become an important factor in the surgical treatment of breast cancer ${ }^{32}$. Women with significant breast asymmetry are more prone to a poorer psychosocial status than those with small asymmetry ${ }^{33}$. In order to maintain symmetry, many patients are submitted to oncological treatment involving OBCS and contralateral symmetrization in the same procedure; however, the literature on the subject is scarce, precluding any conclusions regarding its actual impact on women.

The ideal timing for contralateral breast surgery is after the end of radiotherapy in the index breast, considering the different degrees of volume and elasticity loss and of fibrosis. The index breast volume will continue to change progressively over the years due to the persistent radiation injury. Therefore, the asymmetry assessment should also consider the treatment duration and the moment of symmetrization ${ }^{34}$.

After learning the long-term effects of radiotherapy and the varying degrees of asymmetry, many patients choose to undergo symmetrization and oncological treatment simultaneously; however, the need for symmetrization lacks criteria. In general, the literature has no objective data on the subject, and several authors do not describe the symmetrization rate, which should be part of studies related to BCT and $\mathrm{OBCS}^{34}$.

\section{COSMESIS ASSESSMENT}

The main objective of breast-conserving surgeries is to have local control from an oncological perspective, preserving cosmesis. Nevertheless, surgical resection without adequate reshaping of the remaining parenchyma allows scarring and fibrosis to reveal, after radiotherapy, the unreconstructed cavity, the distortion of the nipple-areola complex, and the uniformity of the parenchyma distribution, which are factors OBCS has overcome ${ }^{34,35}$.

Radiotherapy can cause immediate-to-late alterations, including skin depigmentation, telangiectasias, edema, fibrosis, and changes in breast sensitivity, varying according to dose, irradiated volume, and individual radiosensitivity. In general, combining these changes leads to a progressive reduction in breast volume, affecting the "time" aspect when evaluating breast cosmesis ${ }^{36}$.

OBCS paradigms (oncologic principles associated with plastic improvement) are widely adopted; however, the lack of randomized data makes breast surgeons accept an increasing number 
of series ${ }^{26}$. Tenofsky et al., apud Kosasih et al., when analyzing cosmetic satisfaction among patients submitted to OBCS and BCT, noted that $13.8 \%$ (OBCS group) and 7.1\% (BCT group) were dissatisfied, although without statistical significance $(\mathrm{p}=0.191)^{11}$. In other evaluations, satisfaction with the cosmetic result is higher in the OBCS group than in the BCT one $(89.5 \% \text { vs. } 82.9 \%, \mathrm{p}<0.001)^{12}$.

The main factors associated with breast asymmetry after BCT are age over 60 years, high body mass index, large tumor size, tumors located in the central, inner, or lower quadrants, small breast volume, need for re-excision, breast parenchyma resection greater than $100 \mathrm{~cm}^{3}$, and radiation dose heterogeneity ${ }^{34,35}$. However, in a cohort of 1,035 patients, these factors did not negatively influence the esthetic result. The study showed that wound infection, pain, scar expansion, scars perceptible on palpation, and keloids were associated with a lower cosmetic classification ${ }^{37}$.

Motivated by asymmetry, many patients undergo reconstructive procedures. After this procedure, for example, $94.5 \%$ of patients were satisfied after 1 year and $88.8 \%$ after 5 years, while $19.1 \%$ and $6.4 \%$ required a second and third surgery, respectively ${ }^{38}$. Of note, the cosmetic result may vary during the post-treatment follow-up since the late effects of radiotherapy mentioned above and the change in body mass may directly affect the satisfaction with cosmesis and breast symmetry.

Given the diversity of the procedures available, many cosmetic outcomes can be expected after BCT and OBCS. Thus, the cosmetic evaluation after breast-conserving procedures is relative, with poor rater agreement, which can be minimized after consensus among them. Nonetheless, this scenario hardly occurs in clinical practice ${ }^{39}$.

Cosmetic results can be assessed with objective and subjective tools. Subjective methods take into account the analysis of professionals involved in the treatment, the patient's evaluation, or domains of QoL questionnaires ${ }^{39-41}$. In turn, objective methods consider the measurement of asymmetry between the treated and untreated breast, but there is no universal reference measure. In this scenario, the Breast Cancer Conservative Treatment Cosmetic Results (BCCT.core) software was created to evaluate patients submitted to BCT, using symmetry algorithms, with results calibrated by European experts, showing a great correlation between them. The results are divided into 4 categories (1-excellent, 2-good, 3-fair, 4-poor). This methodology is reproducible and widely used in research ${ }^{42}$. Nevertheless, the software is not available to the general public, with use only in research.

Regarding the effects of radiotherapy in $\mathrm{BCT}$, the Radiation Therapy Oncology Group and the European Organisation for Research and Treatment of Cancer (RTOG/EORTC) scale evaluates cutaneous and subcutaneous changes, while the Late Effects Normal Tissue Task Force/Subjective, Objective, Management, Analytic (LENT/SOMA) scale quantifies telangiectasia, fibrosis, edema, ulceration, breast pigmentation changes, lymphedema, and breast pain, with scores ranging from 0 to $4^{43}$.
The cosmetic results of breast surgery have other forms of evaluation ${ }^{44}$. The Harvard scale, proposed by Harris, initially aimed at evaluating cosmesis after radiotherapy, assessing three main points: skin changes, breast fibrosis/retraction, and radiation-induced alterations, as well as cosmetic evaluation (excellent, good, fair, and poor) ${ }^{45}$. The Garbay scale, which evaluates the results of patients submitted to breast reconstruction ${ }^{46}$ and was later used for patients undergoing $\mathrm{BCT}^{32}$, analyzes breast volume, shape, and height, the inframammary fold, and scarring. It is grouped into four classes and assessed by the numerical sum of the results. The scale by Fitoussi et al. categorizes breast asymmetry and defines a reconstruction classification for contralateral symmetrization ${ }^{38}$.

Despite the different classifications, no consensus has been reached on how to evaluate breast cosmesis after BCT. When comparing BCCT.core with the Harris scale, the results showed a poor association (Kappa $=0.34)^{42}$. In turn, OBCS showed excellent results both in the Harris classification and the BCCT.core. Conversely, several series presented poor agreement between objective and subjective methods and the patient's self-report (usually the patient has a better self-evaluation compared to other methods) ${ }^{32}$.

\section{QUALITY OF LIFE}

Compared to mastectomy, the benefits of breast-conserving surgery are indisputable, particularly because it ensures feminine fulfillment by preserving the normal breast sensation and limiting morbidity in relation to reconstruction by autologous implants or flaps. These benefits increase when adjuvant radiotherapy is administered after mastectomy with reconstruction'. Several studies have shown the advantages of OBCS when it comes to better cosmetic results and patients' satisfaction, although contradictory results have also been reported ${ }^{12}$.

For the vast majority of surgeons, OBCS is strongly associated with improved QoL, but combining the cosmetic result and its benefits from the patient's perspective is quite complex ${ }^{12,24}$.

With the increase in survival, concern with QoL has become routine in oncological treatment for both professionals and patients. Some questionnaires assess the general conditions of oncological treatment (e.g., European Organisation for Research and Treatment of Cancer Core Quality of Life Questionnaire - EORTC QLQ C30, Functional Assessment of Cancer Therapy-General - FACT-G), others are specific for breast cancer (e.g., EORTC QLQ BR23, Functional Assessment of Cancer Therapy-Breast-FACT-B), mastectomy and breast reconstruction (MAS, Michigan Breast Reconstruction Outcome Study - MBROS, BREAST-Q), and BCT (Breast Cancer Treatment Outcome Scale - BCTOS, BREAST-Q) ${ }^{40}$.

EORTC QLQ-C30 is a general questionnaire for cancer patients. It consists of 30 questions divided into 3 dimensions: functional scale, symptom scale associated with 6 unique items (dyspnea, insomnia, loss of appetite, constipation, diarrhea, and financial 
difficulties), and overall QoL. Like QLQ-C30, QLQ-BR23 scores are converted from $0-100$ and follow the same reasoning for interpretation. EORTC QLQ-BR23 is a QoL questionnaire specific to breast cancer patients. Validated in Portuguese, it has 23 questions divided into 2 dimensions - functional scale and symptom scale - and uses a 4-point scale to obtain the score (not at all, a little, quite a bit, and very much) ${ }^{47}$.

Comparing the QoL of 485 patients submitted to BCT, 46 to mastectomy with immediate reconstruction, and 87 to mastectomy without reconstruction 1 year after treatment using the QLQC30 and QLQ-BR23 questionnaires, those who underwent BCT and immediate reconstruction showed better scores as to social function, general function, and body image. At the same time, the comparison of these two groups (BCT and reconstruction) presented no difference regarding objective cosmetic effects, except for body image in QLQ-BR23 ${ }^{48}$. Another study used the QLQ-C30 and QLQ-BR23 questionnaires to assess the QoL of patients submitted to $\mathrm{BCT}(\mathrm{n}=76)$ and to mastectomy without $(\mathrm{n}=20)$ and with $(\mathrm{n}=16)$ reconstruction. The authors identified that those who underwent BCT had better body image and were more satisfied than the other groups ${ }^{49}$.

$\mathrm{BCTOS}^{50}$, aimed at the subjective evaluation of esthetic and functional results after BCT, has questions about functional status, cosmetic status, breast-specific pain, and edema. It comprises 22 items -8 questions related to breast shape and volume, 7 to shoulder/arm movement, 4 to arm volume, and 3 to breast pain and sensitivity ${ }^{33}$. These questions are scored from 1 to 4 points 1 point meaning no difference between the treated and untreated breast or area and 4 points corresponding to a great difference between the treated and untreated breast or area. This questionnaire was translated into Brazilian Portuguese and validated ${ }^{41}$.

BCTOS has proven to be effective in patients submitted to conservative treatment associated with radiotherap ${ }^{50}$. BCTOS cosmetic results were compared with those of BCCT.core with high agreement, but patients presented higher rates of cosmetic satisfaction in BCTOS than in the software ${ }^{51}$.

Another questionnaire developed is the Breast- $Q$, initially designed to evaluate breast surgery ${ }^{52}$ and used in both plastic and reconstructive surgery. It is divided into six domains: satisfaction with breasts, general outcomes, care experience, psychosocial, physical, and sexual well-being. The second version of this questionnaire, created to evaluate BCT, has not been translated into Brazilian Portuguese yet, with few studies using it ${ }^{53}$. The literature has validation studies of the electronic version ${ }^{54}$ and for the Japanese population, but not for a Brazilian version.

International study administering Breast- $Q$ to patients submitted to mastectomy with and without reconstruction and to $\mathrm{BCT}$ revealed that the mastectomy with reconstruction group had better scores in the sexual well-being domain than the BCT and mastectomy without reconstruction groups. However, no difference was found in the psychosocial domain ${ }^{55}$; therefore, immediate reconstruction is related to better Breast- $Q$ scores ${ }^{56}$.
In the literature, comparing objective results evaluated by objective and reproducible QoL instruments has proven to be difficult. Exner et al. ${ }^{57}$ used the Breast Analyzing Tool (BAT) to objectively evaluate the breast symmetry of 101 patients submitted to BCT, correlating the results with the QoL measured by the Breast Image Scale (BIS) and the EORTC QLQ-BR23. They found no direct association between symmetry and the patients' QoL.

The level of satisfaction does not necessarily reflect the degree of symmetry: women with normal breasts may be dissatisfied with them ${ }^{58}$. In general, QoL studies are not associated with objective results, and selection bias might occur when evaluating patients submitted to OBCS. Despite the apparent similarity between groups, previous choices have been made, leading to the selection of younger, better educated, and more inquisitive patients for OBCS.

By comprising a wide range of oncological and reconstructive surgical procedures, oncoplastic surgery - with or without symmetrization - allows the reduction of both the affected and the contralateral breast, which can be performed immediately, in stages, or later, with no differences in QoL between groups ${ }^{59}$. We underline that the patient's analysis of these results requires a gold standard, and the current methods can vary considerably in both cosmetic and functional evaluation ${ }^{60}$.

\section{CONCLUSION}

Oncoplastic surgery increased the indications for breast-conserving treatment while maintaining oncological safety. As a result, OBCS favors breast preservation, increasing female satisfaction, which can positively impact cosmetic and QoL results.

\section{Research ethics}

As a literature review, this study does not require evaluation by the Research Ethics Committee, according to Resolution 466/2012.

The patients authorized the use of their images in scientific publications by signing the Informed Consent Form of a study approved by the Research Ethics Committee of the Hospital de Câncer de Barretos, under number 782/2014.

\section{ACKNOWLEDGMENTS}

To Fabiola Cristina Brandini da Silva for taking the pictures.

\section{AUTHORS' CONTRIBUTIONS}

I.O.J.: conceptualization, data curation, formal analysis, investigation, methodology, writing - original draft, writing - review \& editing. R.L.H.: conceptualization, writing - original draft, writing - review \& editing. R.A.C.V.: conceptualization, data curation, formal analysis, investigation, methodology, writing - original draft, writing - review \& editing. 
1. Kopkash K, Clark P. Basic Oncoplastic Surgery for Breast Conservation: Tips and Techniques. Ann Surg Oncol. 2018;25(10):2823-8. https://doi.org/10.1245/s10434-018-6604-5

2. Fisher B, Anderson S, Bryant J, Margolese RG, Deutsch M, Fisher ER, et al. Twenty-year follow-up of a randomized trial comparing total mastectomy, lumpectomy, and lumpectomy plus irradiation for the treatment of invasive breast cancer. New Engl J Med. 2002;347(16):1233-41. https://doi.org/10.1056/ nejmoa022152

3. Mora LD. History of Surgical Treatment of Breast Cancer Empiricism and Science. Rev Port Cir. 2013;(27):41-58.

4. Vieira RA, Carrara GF, Scapulatempo Neto C, Morini MA, Brentani MM, Folgueira MA. The role of oncoplastic breast conserving treatment for locally advanced breast tumors. A matching case-control study. Ann Med Surg (Lond). 2016;10:618. https://dx.doi.org/10.1016\%2Fj.amsu.2016.08.001

5. Clough KB, Cuminet J, Fitoussi A, Nos C, Mosseri V. Cosmetic sequelae after conservative treatment for breast cancer: classification and results of surgical correction. Ann Plast Surg. 1998;41(5):471-81. https://doi.org/10.1097/00000637199811000-00004

6. Oliveira-Junior I, Silva IA, Silva FCB, Silva JJ, Sarri AJ, Paiva CE, et al. Oncoplastic Surgery in Breast-Conserving Treatment. Patient Profile and impact on quality of life. Breast Care. 2020. https://doi.org/10.1159/000507240

7. Silverstein MJ, Savalia N, Khan S, Ryan J. Extreme oncoplasty: breast conservation for patients who need mastectomy. Breast J. 2015;21(1):52-9. https://doi.org/10.1111/tbj.12356

8. Clough KB, Benyahi D, Nos C, Charles C, Sarfati I. Oncoplastic surgery: pushing the limits of breast-conserving surgery. Breast J. 2015;21(2):140-6. https://doi.org/10.1111/tbj.12372

9. Patel K, Bloom J, Nardello S, Cohen S, Reiland J, Chatterjee A. An Oncoplastic Surgery Primer: Common Indications, Techniques, and Complications in Level 1 and 2 Volume Displacement Oncoplastic Surgery. Ann Surg Oncol. 2019;26(10):3063-70. https://doi.org/10.1245/s10434-019-07592-5

10. Paulinelli RR, Oliveira VM, Bagnoli F, Chade MC, Alves KL, Freitas-Junior R. Oncoplastic mammaplasty with geometric compensation--a technique for breast conservation. J Surg Oncol. 2014;110(8):912-8. https://doi.org/10.1002/jso.23751

11. Kosasih S, Tayeh S, Mokbel K, Kasem A. Is oncoplastic breast conserving surgery oncologically safe? A meta-analysis of 18,103 patients. Am J Surg. 2020;220(2):385-92. https://doi. org/10.1016/j.amjsurg.2019.12.019

12. Losken A, Dugal CS, Styblo TM, Carlson GW. A metaanalysis comparing breast conservation therapy alone to the oncoplastic technique. Ann Plast Surg. 2014;72(2):145-9. https://doi.org/10.1097/sap.0b013e3182605598

13. Down SK, Jha PK, Burger A, Hussien MI. Oncological advantages of oncoplastic breast-conserving surgery in treatment of early breast cancer. Breast J. 2013;19(1):56-63. https://doi.org/10.1111/tbj.12047

14. CutressRI,SummerhayesC,RainsburyR.Guidelinesforoncoplastic breast reconstruction. Ann R Coll Surg Engl. 2013;95(3):161-2. https://doi.org/10.1308/003588413x13511609957696
15. Rietjens M, Urban CA, Rey PC, Mazzarol G, Maisonneuve $\mathrm{P}$, Garusi $\mathrm{C}$, et al. Long-term oncological results of breast conservative treatment with oncoplastic surgery. Breast. 2007;16(4):387-95. https://doi.org/10.1016/j.breast.2007.01.008

16. Chakravorty A, Shrestha AK, Sanmugalingam N, Rapisarda F, Roche N, Querci Della Rovere G, et al. How safe is oncoplastic breast conservation? Comparative analysis with standard breast conserving surgery. Eur J Surg Oncol. 2012;38(5):395-8. https://doi.org/10.1016/j.ejso.2012.02.186

17. Clough KB, van la Parra RFD, Thygesen HH, Levy E, Russ E, Halabi NM, et al. Long-term Results After Oncoplastic Surgery for BreastCancer:A 10-year Follow-up.AnnSurg. 2018;268(1):16571. https://doi.org/10.1097/sla.0000000000002255

18. Chen JY, Huang YJ, Zhang LL, Yang CQ, Wang K. Comparison of Oncoplastic Breast-Conserving Surgery and BreastConserving Surgery Alone: A Meta-Analysis. J Breast Cancer. 2018;21(3):321-9. https://doi.org/10.4048/jbc.2018.21.e36

19. Munhoz AM, Montag E, Gemperli R. Current aspects of therapeutic reduction mammaplasty for immediate early breast cancer management: An update. World J Clin Oncol. 2014;5(1):1-18. https://doi.org/10.5306/wjco.v5.i1.1

20. Borm KJ, Schonknecht C, Nestler A, Oechsner M, Waschulzik B, Combs SE, et al. Outcomes of immediate oncoplastic surgery and adjuvant radiotherapy in breast cancer patients. BMC Cancer. 2019;19(1):907. https://doi.org/10.1186/s12885019-6104-4

21. Andrade Urban C. New classification for oncoplastic procedures in surgical practice. Breast. 2008;17(4):321-2. https://doi.org/10.1016/j.breast.2007.11.032

22. Clough KB, Kaufman GJ, Nos C, Buccimazza I, Sarfati IM. Improving breast cancer surgery: a classification and quadrant per quadrant atlas for oncoplastic surgery. Ann Surg Oncol. 2010;17(5):1375-91. https://doi.org/10.1245/s10434-009-0792-y

23. Chatterjee A, Gass J, Patel K, Holmes D, Kopkash K, Peiris L, et al. A Consensus Definition and Classification System of Oncoplastic Surgery Developed by the American Society of Breast Surgeons. Ann Surg Oncol. 2019;26(11):3436-44. https:// doi.org/10.1245/s10434-019-07345-4

24. Weber WP, Soysal SD, El-Tamer M, Sacchini V, Knauer M, Tausch C, et al. First international consensus conference on standardization of oncoplastic breast conserving surgery. Breast Cancer Res Treat. 2017;165(1):139-49. https://doi. org/10.1007/s10549-017-4314-5

25. Hoffmann J, Wallwiener D. Classifying breast cancer surgery: a novel, complexity-based system for oncological, oncoplastic and reconstructive procedures, and proof of principle by analysis of 1225 operations in 1166 patients. BMC Cancer. 2009;9:108. https://doi.org/10.1186/1471-2407-9-108

26. Weber WP, Soysal SD, Fulco I, Barandun M, Babst D, Kalbermatten D, et al. Standardization of oncoplastic breast conserving surgery. Eur J Surg Oncol. 2017;43(7):1236-43. https://doi.org/10.1016/j.ejso.2017.01.006

27. Zucca Matthes AG, Viera RA, Michelli RA, Ribeiro GH, Bailao A, Jr., Haikel RL, et al. The development of an Oncoplastic Training Center - OTC. Int J Surg. 2012;10(5):265-9. https://doi. org/10.1016/j.ijsu.2012.03.009 
28. Munhoz AM, Montag E, Gemperli R. Oncoplastic breast surgery: indications, techniques and perspectives. Gland Surg. 2013;2(3):14357. https://doi.org/10.3978/j.issn.2227-684x.2013.08.02

29. Clough KB, Ihrai T, Oden S, Kaufman G, Massey E, Nos C. Oncoplastic surgery for breast cancer based on tumour location and a quadrant-per-quadrant atlas. Br J Surg. 2012;99(10):1389-95. https://doi.org/10.1002/bjs.8877

30. Silverstein MJ, Mai T, Savalia N, Vaince F, Guerra L. Oncoplastic breast conservation surgery: the new paradigm. J Surg Oncol. 2014;110(1):82-9. https://doi.org/10.1002/jso.23641

31. Silverstein MJ, Savalia NB, Khan S, Ryan J, Epstein M, DeLeon C, et al. Oncoplastic Split Reduction with Intraoperative Radiation Therapy. Ann Surg Oncol. 2015;22(10):3405-6. https://doi.org/10.1245/s10434-015-4671-4

32. Santos G, Urban C, Edelweiss MI, Zucca-Matthes G, de Oliveira VM, Arana GH, et al. Long-Term Comparison of Aesthetical Outcomes After Oncoplastic Surgery and Lumpectomy in Breast Cancer Patients. Ann Surg Oncol. 2015;22(8):2500-8. https://doi.org/10.1245/s10434-014-4301-6

33. Stanton AL, Krishnan L, Collins CA. Form or function? Part 1. Subjective cosmetic and functional correlates of quality of life in women treated with breast-conserving surgical procedures and radiotherapy. Cancer. 2001;91(12):2273-81.

34. Savalia NB, Silverstein MJ. Oncoplastic breast reconstruction: Patient selection and surgical techniques. J Surg Oncol. 2016;113(8):875-82. https://doi.org/10.1002/jso.24212

35. Hennigs A, Hartmann B, Rauch G, Golatta M, Tabatabai P, Domschke C, et al. Long-term objective esthetic outcome after breast-conserving therapy. Breast Cancer Res Treat. 2015;153(2):345-51. https://doi.org/10.1007/s10549-015-3540-y

36. Wazer DE, DiPetrillo T, Schmidt-Ullrich R, Weld L, Smith TJ, Marchant DJ, et al. Factors influencing cosmetic outcome and complication risk after conservative surgery and radiotherapy for early-stage breast carcinoma. J Clin Oncol. 1992;10(3):35663. https://doi.org/10.1200/jco.1992.10.3.356

37. Rezai M, Knispel S, Kellersmann S, Lax H, Kimmig R, Kern P. Systematization of Oncoplastic Surgery: Selection of Surgical Techniques and Patient-Reported Outcome in a Cohort of 1,035 Patients. Ann Surg Oncol. 2015;22(11):3730-7. https://doi. org/10.1245/s10434-015-4396-4

38. Fitoussi AD, Berry MG, Couturaud B, Falcou MC, Salmon RJ. Management of the post-breast-conserving therapy defect: extended follow-up and reclassification. Plast Reconstr Surg. 2010;125(3):783-91. https://doi.org/10.1097/prs.0b013e3181ccda68

39. Cardoso MJ, Cardoso J, Santos AC, Barros H, Cardoso de Oliveira $\mathrm{M}$. Interobserver agreement and consensus over the esthetic evaluation of conservative treatment for breast cancer. Breast. 2006;15(1):52-7. https://doi.org/10.1016/j.breast.2005.04.013

40. Chen CM, Cano SJ, Klassen AF, King T, McCarthy C, Cordeiro PG, et al. Measuring quality of life in oncologic breast surgery: a systematic review of patient-reported outcome measures. BreastJ. 2010;16(6):587-97. https://doi.org/10.1111/j.1524-4741.2010.00983.x

41. Brandini da Silva FC, Jose da Silva J, Sarri AJ, Paiva CE, Aloisio da Costa Vieira R. Comprehensive Validation Study of Qualityof-Life Questionnaire Using Objective Clinical Measures: Breast Cancer Treatment Outcome Scale (BCTOS), Brazilian Portuguese Version. Clin Breast Cancer. 2019;19(1):e85-e100. https://doi.org/10.1016/j.clbc.2018.10.004
42. Cardoso MJ, Cardoso J, Amaral N, Azevedo I, Barreau L, Bernardo M, et al. Turning subjective into objective: the BCCT. core software for evaluation of cosmetic results in breast cancer conservative treatment. Breast. 2007;16(5):456-61. https://doi.org/10.1016/j.breast.2007.05.002

43. Hoeller U, Tribius S, Kuhlmey A, Grader K, Fehlauer F, Alberti $\mathrm{W}$. Increasing the rate of late toxicity by changing the score? A comparison of RTOG/EORTC and LENT/SOMA scores. Int J Radiat Oncol Biol Phys. 2003;55(4):1013-8. https://doi. org/10.1016/s0360-3016(02)04202-5

44. Santos G, Urban C, Edelweiss MI, Kuroda F, Capp E. Evaluation of the aesthetical and quality of life results after breast cancer surgery. Rev Bras Mastol. 2013;23(3):60-8.

45. Harris JR, Levene MB, Svensson G, Hellman S. Analysis of cosmetic results following primary radiation therapy for stages I and II carcinoma of the breast. Int J Radiat Oncol Biol Phys. 1979;5(2):257-61. https://doi.org/10.1016/03603016(79)90729-6

46. Garbay JR, Rietjens M, Petit JY. [Esthetic results of breast reconstruction after amputation for cancer. 323 cases]. J Gynecol Obstet Biol Reprod (Paris). 1992;21(4):405-12.

47. Michels FA, Latorre M do R, Maciel M do S. Validity, reliability and understanding of the EORTC-C30 and EORTC-BR23, quality of life questionnaires specific for breast cancer. Rev Bras Epidemiol. 2013;16(2):352-63. https://doi.org/10.1590/ S1415-790X2013000200011

48. Kim MK, Kim T, Moon HG, Jin US, Kim K, Kim J, et al. Effect of cosmetic outcome on quality of life after breast cancer surgery. Eur J Surg Oncol. 2015;41(3):426-32. https://doi.org/10.1016/j. ejso.2014.12.002

49. Han J, Grothuesmann D, Neises M, Hille U, Hillemanns P. Quality of life and satisfaction after breast cancer operation. Arch Gynecol Obstet. 2010;282(1):75-82. https://doi. org/10.1007/s00404-009-1302-y

50. Krishnan L, Stanton AL, Collins CA, Liston VE, Jewell WR. Form or function? Part 2. Objective cosmetic and functional correlates of quality of life in women treated with breastconserving surgical procedures and radiotherapy. Cancer. 2001;91(12):2282-7.

51. Heil J, Dahlkamp J, Golatta M, Rom J, Domschke C, Rauch G, et al. Aesthetics in breast conserving therapy: do objectively measured results match patients' evaluations? Ann Surg Oncol. 2011;18(1):134-8. https://doi.org/10.1245/s10434-010$1252-4$

52. Pusic AL, Klassen AF, Scott AM, Klok JA, Cordeiro PG, Cano SJ. Development of a new patient-reported outcome measure for breast surgery: the BREAST-Q. Plast Reconstr Surg. 2009;124(2):345-53. https://doi.org/10.1097/ prs.0b013e3181aee 807

53. O’Connell RL, DiMicco R, Khabra K, O’Flynn EA, de Souza $\mathrm{N}$, Roche $\mathrm{N}$, et al. Initial experience of the BREAST-Q breast-conserving therapy module. Breast Cancer Res Treat. 2016;160(1):79-89. https://doi.org/10.1007/s10549016-3966-x

54. Fuzesi S, Cano SJ, Klassen AF, Atisha D, Pusic AL. Validation of the electronic version of the BREAST-Q in the army of women study. Breast. 2017;33:44-9. https://doi.org/10.1016/j. breast.2017.02.015 
55. Howes BH, Watson DI, Xu C, Fosh B, Canepa M, Dean NR. Quality of life following total mastectomy with and without reconstruction versus breast-conserving surgery for breast cancer: A case-controlled cohort study. J Plast Reconstr Aesthet Surg. 2016;69(9):1184-91. https://doi.org/10.1016/j.bjps.2016.06.004

56. Rosson GD, Shridharani SM, Magarakis M, Manahan MA, Basdag B, Gilson MM, et al. Quality of life before reconstructive breast surgery: A preoperative comparison of patients with immediate, delayed, and major revision reconstruction. Microsurgery. 2013;33(4):253-8. https://doi.org/10.1002/micr.22081

57. Exner R, Krois W, Mittlbock M, Dubsky P, Jakesz R, Gnant M, et al. Objectively measured breast symmetry has no influence on quality of life in breast cancer patients. Eur J Surg Oncol. 2012;38(2):130-6. https://doi.org/10.1016/j.ejso.2011.10.012
58. Matthes A do C, Sgrignoli RB. Definition of mammary eutrophy for womeninthemenacme.RevLatino-AmEnfermagem.2009;17(1):10812.http://dx.doi.org/10.1590/S0104-11692009000100017

59. Patel KM, Hannan CM, Gatti ME, Nahabedian MY. A head-to-head comparison of quality of life and aesthetic outcomes following immediate, staged-immediate, and delayed oncoplastic reduction mammaplasty. Plast Reconstr Surg. 2011;127(6):2167-75. https://doi.org/10.1097/ prs.0b013e3182131clc

60. Heil J, Czink E, Golatta M, Schott S, Hof H, Jenetzky E, et al. Change of aesthetic and functional outcome over time and their relationship to quality of life after breast conserving therapy. Eur J Surg Oncol. 2011;37(2):116-21. https://doi. org/10.1016/j.ejso.2010.11.007 